(C2018, Elsevier. Licensed under the Creative Commons Attribution-NonCommercialNoDerivatives 4.0 International http://creativecommons.org/about/downloads

cc) $(1) \Theta$ 


\title{
Fund me to the Moon: Crowdfunding and the New Space economy
}

\section{Caleb Pomeroya.b}

(Corresponding author; email: pomeroy.38@osu.edu)

\author{
Abigail Calzada-Diaz, \\ (acalza01@mail.bbk.ac.uk) \\ Damian Bielicki ${ }^{\mathrm{b}, \mathrm{d}}$ \\ (Damian.Bielicki@kingston.ac.uk)
}

Department of Political Science, University College London, 30 Tavistock Square, London WC1H 9QU, United Kingdom

'Space Exploration Working Group, Space Generation Advisory Council, c/o European Space Policy Institute, Schwarzenbergplatz 6, 1030 Vienna, Austria

Department of Earth and Planetary Sciences, Birkbeck College, University of London, Malet Street, London WC1E 7HX, United Kingdom

`Kingston University London, Kingston Hill, Kingston-upon-Thames, Surrey KT2 7LB, United Kingdom

\begin{abstract}
The likes of Elon Musk and Jeff Bezos now occupy the headlines once dominated by Apollo and Soyuz. Described as New Space versus Old Space, debate surrounds the emerging commercial space industry and the role of nontraditional actors in the evolving contemporary space exploration environment. This article enters this debate by adopting a sociological approach to investigate the role of crowdfunding in financing space exploration today. We interview crowdfunded space project creators in disparate locations, from Moscow to Silicon Valley, who attracted capital ranging from \$200 to over \$1 million. We attempt to uncover their experiences using this distinctly social financing mechanism and find that although crowdfunding is unlikely to solve all of today's research funding conundrums, it does appear to increase access to space in unique ways. We argue, however, that the most interesting dynamic of this phenomenon is the way in which crowdfunding contributes to an increasingly democratic exploration environment and how this might impact space science research and the power structures of the space industry. This article concludes by considering possible implications of this trend and derives practical suggestions for both policymakers and individuals who may be considering the use of crowdfunding to finance space science research and exploration projects.
\end{abstract}

Keywords

Crowdfunding, New Space, space exploration, democratization, science and technology policy. 


\section{Introduction}

When Buzz Aldrin played Frank Sinatra's recording of "Fly Me to the Moon" from our lunar surface, the budget of the National Aeronautics and Space Administration (NASA) was at historically high levels. The United States (US) raced against the Soviet Union and its counterpart Soyuz program. Space was accessible to only a handful of the wealthiest states who were willing and able to allocate billions of dollars to large-scale, decade(s) long research and exploration initiatives. Though often shrouded in political and ideological discourse, the Cold War Space Race opened a new frontier for human exploration and pioneered research and technology which still benefit the space sciences today [1] and [2].

Although the Apollo program is long retired and US spending on space has substantially declined since [3], nontraditional space actors - from entrepreneurs to enthusiasts - have never been more active. In 2008, Elon Musk's SpaceX and Orbital Sciences Corporation received \$3.5 billion in contracts to shuttle US payloads to the International Space Station (ISS), and in 2014, Boeing and SpaceX received $\$ 6.8$ billion in contracts to taxi American astronauts to the ISS [4]. An increasing number of space tourism operations, such as Virgin Galactic and XCOR Aerospace, have attracted significant funding with the promise of orbital and suborbital flights at a fraction of present rates [5]. A panel at the 66" International Astronautical Conference even discussed the implications of the "New Space economy," and Goldman Sachs goes so far as to describe this as the ignition of a second space race [6].

We use the term "New Space" - sometimes referred to as alt.space, emerging space, space 2.0, and entrepreneurial space - to refer to the increasing presence of nontraditional space actors, such as entrepreneurs, enthusiasts, and hybrid public-private organizations, in the utilization, exploration, and commercialization of outer space. Pioneered by arts and music communities [7], crowdfunding has emerged as a source of capital for such projects ranging from classroom telescopes to the colonization of Mars. While the economics and managerial science literatures have taken first steps towards investigating crowdfunding, e.g. [8] and [9], less research considers the experiences of individuals using this distinctly social financing mechanism, and almost no attention has been paid to crowdfunding in the context of space science research and exploration. This begs the question: what is the role of crowdfunding in financing space science research and exploration today?

To explore this question, we conduct in-depth, semi-structured interviews with crowdfunded space project creators - including finance directors, entrepreneurs, scientists, enthusiasts, and students located in seven different countries and who raised capital ranging from $\$ 200$ to over $\$ 1$ million. While existing commentary shares a devotion to analyzing New Space activities in commercial and financial terms, we draw upon the Science and Technology Studies literature to argue that the evolving nature of today's space exploration environment is best understood as an exercise in democratization and an exercise to which crowdfunding contributes. We find that while crowdfunding is unlikely to solve all of today's space financing conundrums, it can indeed increase access to space for both traditional and nontraditional actors. Beyond this, however, we take a step back and consider the implications of this phenomenon for today's space science research and exploration environment, specifically the ways in which crowdfunding might constrain and enable certain types of research and how existing power structures of the space industry might be impacted as a result.

This paper is structured as follows: first, we discuss the conditions which create scope for nontraditional space actors to become increasingly active in space and how crowdfunded space projects have emerged as a result. Second, we outline the Science and Technology Studies literature on democratization which provides a starting point for investigating this phenomenon from a sociological perspective. The data and interview strategy are then described before presenting the results of the interviews. The final 
section discusses these findings and derives practical suggestions for both policymakers and individuals who may be considering using crowdfunding before concluding.

\section{The New Space economy and the emergence of crowdfunding}

Post-Cold War space policy adjustments have structurally changed the exploration environment. Although the commercial sector has operated in space since the 1962 launch of Telstar 1, which transmitted television signals across the Atlantic Ocean, involvement today is at historically high levels. To understand this trend, we should consider the conditions which created scope for such change.

Government funding for space programs have generally decreased, and the grants which traditionally bolstered space science research have declined [10], [11], and [12]. More recently, Jarritt et al [13] explain that scope for US commercial activity may have widened following the 2007 financial crisis and the subsequent search for more commercial partners. Kessler and Peeters [14] point to regulatory adjustments, such as the Obama administration's decision to commercialize access to the ISS and revisit International Traffic in Arms Regulations. Furthermore, in 2015, the SPACE Act passed the US Congress which allows "US citizens to engage in the commercial exploration and exploitation of "space resources'..." [15].

These events and decisions have increased scope for commercial activity in space. Kessler and Peeters [16] explain that this evolving environment is characterized by increased commercialization independent of government initiatives, the rise of public-private partnerships, and increased global competition from new space-capable states. They point to novel initiatives like SpaceX and the Google Lunar Prize as illustrative of this trend [17]. Firms are developing technologies necessary to extract resources from asteroids [18], and space tourism operations are working to expand private spaceflight. In the United Kingdom, the 2016 Queen's Speech to Parliament describes legislative measures to develop the country's first commercial spaceport, and some twenty other countries plan to develop ports to service commercial launches and space tourism operations [19].

This common New Space narrative, however, tends to overlook the actors operating outside of largescale commercial ventures but within this evolving exploration environment. For example, the decreasing costs of satellites and government initiatives to offer complimentary launches for science projects have brought other nontraditional space actors into the fold. In 2013 the first nanosatellites ever developed by high school students were launched by NASA through the CubeSat Launch Initiative [20]. To fund these sorts of initiatives, Platzer and Klausner [21] explain that individuals and small companies who might have faced barriers in raising capital for space projects through traditional bank loans, venture capital, or angel investment, have successfully turned to crowdfunding to raise funds and foster citizen engagement.

Crowdfunding is a centuries old fundraising concept which has been catalyzed by the commercialization of the internet in the last decade and a half. A project creator appeals to potential funders (the "crowd") via online platforms for capital in the form of loans, donations, equity purchases, or the pre-ordering of a specified product [22]. These online platforms allow for relatively efficient matching of creators and funders, the aggregation of small donations into large pools of capital, and tend to lower the geographic barriers to fundraising [23] and [24].

Economists and managerial scientists who explore the empirics of crowdfunding have found that funding propensity tends to increase with accumulated capital which may lead to herding [25] and that backers are more likely to contribute to a project in the first and last weeks of the campaign [26]. Project funding success is found to be a function of personal networks [27], [28], and [29], the required donation 
price, and competition from similar projects [30]. We know much less, however, about the sociological dimensions of crowdfunding in general and even less about these dimensions in the context of crowdfunded space projects.

Platzer and Klausner [31] argue that crowdfunding has been "undeniably successful in driving citizen engagement and money towards space projects." Media attention paid to crowdfunded space projects has also been relatively optimistic but largely directed towards only the few most successful cases, e.g. [22] and [33]. According to representatives from the platform Kickstarter, 185 space-related campaigns have indeed received $\$ 9.7$ million in pledges as of 2015 , but this constitutes only a small portion of the 235,000 total Kickstarter projects which have received $\$ 1.75$ billion in pledges [34]. As Harris and Russo [35] point out, anecdotal evidence exists that crowdfunding can open avenues for public engagement with space policy, but additional investigation is necessary. This distinctly social financing mechanism presents an opportunity to examine the role of this mechanism in financing space science research and exploration today, as well as the social dimensions of New Space activities.

\subsection{Democratizing space science research and exploration}

Scholars of Science and Technology Studies have developed a vibrant research program aimed at problematizing assumptions about the nature of technological development, the democratization of science, and the impact of public participation on the production of science and technology policy, e.g. [36], [37], and [38]. A core interest in this research involves the nature of democratizing otherwise traditional, exclusive, and elitist forms of science, as well as the implications of technological change for governance and the role of public participation within this process [39] and [40]. It is argued that deliberative processes can result in a more meritocratic form of science which increases the quality, effectiveness, and legitimacy of solutions to societal problems [41]. As Laird [42] explains, "Discussion about who we are, what we want, and how we might get it are fundamental to any democratic discourse." Opening avenues for deliberation and communication can encourage this process [43] and [44].

By this measure, we might expect crowdfunding to contribute to increased levels of public involvement in space: the crowd "votes" with their donations on the types of research and exploration projects to fund, and online platforms encourage open communication between donor and researcher. At the same time, Turnhout et al [45] point out that avenues linking the public with the scientific production of knowledge require scrutiny, such as questioning the power relations that emerge in the process. In terms of the role of financing, Fochler [46] finds that a divide can exist between the production of scientific research and the commercial logic of venture capital. Commercialization might beg questions regarding the ways in which research is conducted, presented, and marketed to attract funding but can produce unique epistemic spaces for research beyond the traditional academia-corporate world divide [47]. Lehoux et al [48] similarly investigate the ways in which venture capitalists decide which medical technologies to fund and thus bring into existence. Crowdfunding therefore presents an interesting point of inquiry at the intersection of public involvement and the financing of space science research and exploration.

While existing commentary largely analyzes New Space activities in commercial and financial terms, this literature provides grounds to view today's evolving space exploration environment as an exercise in democratization and an exercise to which crowdfunding contributes. We argue that crowdfunding promotes the democratization of space science research and exploration - that is, it expands the role of the public in financing and participating in space - with at least two interesting implications. 
First, crowdfunding requires that scientists learn to market and communicate their research in ways that government research grant applications do not require. Byrnes et al [49] look at scientists' turn to crowdfunding amidst declining government research grants and find that scientists must build a "fanbase" audience to enjoy support, and Hui and Gerber [50] similarly argue that although scientists might feel autonomous vis-à-vis the constraints of traditional grants, crowdfunding also pushes scientists to communicate the merits of their research to a broad audience and adapt to the responsibilities of managing a campaign. This might constrain and enable certain types of research and begs inquiry into the nature of incentivizing the public to donate to research in return for gifts. While crowdfunding can enable research that may have previously gone unfunded, we expect that space scientists and engineers might face similar constraints when attempting to market their research to the public.

Second, crowdfunding enables new actors while possibly pressing upon the traditionally rigid power structures of the space industry. Kaminski [51] posits that in the case of US space exploration, a relatively small, elite cohort dominates policy and direction: politicians, scientists, and corporations. She explores avenues through which citizens might become more involved in developing space policy. On one hand, crowdfunding helps democratize space science research and exploration by allowing nontraditional actors like student groups and individual enthusiasts to access capital required to fund certain types of exploration. On the other hand, traditional actors are also impacted as policymakers work to regulate crowdfunding and develop policy for an increasingly crowded outer space. Scientists have used crowdfunding as a substitute for government grants. Private companies have used crowdfunding to raise capital for profit-seeking ventures. In each case, citizens - the fourth actor Kaminski seeks to incorporate into space policy development - are directly involved in shaping outcomes. The JOBS Act [52] was a retrospective regulatory adjustment in response to increasing citizen use of crowdfunding, and citizens "vote" with their donations on the research initiatives and private ventures to be funded. Crowdfunding may thus challenge the power structures of the space industry in cases where new actors utilize this mechanism to gain access to space.

For this study, the important takeaway from the Science and Technology Studies literature is a commitment to questioning our assumptions and considering the social dimensions of technological development. To appreciate the changing nature of space and the ways in which crowdfunding might contribute to this change, we need to investigate the human dimension of this phenomenon. We need to consider individuals' perceived experiences, troubles, and successes. Who is left out, and who is included? What are the potential positive and negative implications which might result from crowdfunding's democratization effects? To approach these questions, we gather primary accounts from individuals who operate in this evolving space environment.

\section{Data and method}

To investigate the role of crowdfunding in financing space science research and exploration, we conducted in-depth, semi-structured interviews with individuals who have previously utilized crowdfunding. Potential interviewees were located by searching through all available active and archived space exploration projects listed on all major online crowdfunding platforms up to August 2016. From the list of space exploration projects, a subset of projects which included a substantive science, engineering, or research component was identified. In the end, 40 interview invitations were sent via email. From this potential sample, 14 individuals responded and were successfully interviewed for a yield of $35 \%$. 
This sample provides a varied account of the range of experiences of actors operating in this new exploration environment. The individuals included finance directors, entrepreneurs, scientists, enthusiasts, and students who were sometimes a combination of these roles. Projects hailed from seven different countries, including the US, the UK, Canada, Australia, Russia, Denmark, and the Netherlands, and capital raised ranged from approximately $\$ 210$ to $\$ 1,060,000$ in adjusted 2016 dollars. When factoring in multiple campaigns for the same project, 12 projects reached their goals, six did not reach their goals, and seven different crowdfunding platforms were used. Most projects involved the launch of a physical asset into space with goals ranging from research to consumer applications. All interviewees used donation or rewards-based models, i.e. our sample includes no projects using loan or equity-based models.

Each interviewee received a cover letter detailing the goal of our paper and information about the interview. The interviews were conducted over Skype or mobile phone except for two interviewees who opted to submit email responses. Each interview began with outlining standard ethics considerations and the receipt of permission to audio record the interviews for the purposes of drafting the paper. The interview questions first covered the professional background of the interviewee, how they became involved in the given project, and why they chose crowdfunding as a financing mechanism. Subsequent questions attempted to uncover the role of regulation and specific pros and cons of crowdfunding versus traditional financing mechanisms. Finally, ample time was allocated to an open response section in which interviewees discussed any topics that they felt were pertinent.

The method of semi-structured interviews allowed us to concentrate on a pre-decided set of important topics while maintaining the flexibility to deviate from and react to unexpected turns in the conversations. As an exploratory study with little previous research to draw upon, the questions were designed to be open-ended in order to capture the interviewees' first-hand accounts of their experiences, perceptions, troubles, and successes. Although our sample size inhibits claims of generalizability, this semi-structured approach allows us to capture more nuanced details of the participants' experiences compared to a structured interview or survey approach. The interviews lasted between approximately 30 minutes to one hour and 10 minutes, with an average of about 40 minutes. Although compensation was not given, an option to include the interviewee's name and organization in this paper's appendix was offered. Each interviewee was assured that the results would be presented anonymously, however, in order to create an environment suitable for a candid conversation in which sensitive details and personal experiences could be shared. Notes and audio recordings from the interviews were subsequently reviewed, theory was consulted, and results were organized into emergent themes in an iterative process.

\section{Findings}

This section thematically presents the findings of our interviews with creators of crowdfunding campaigns for space science research and exploration projects. Though segmented into three sections, most findings are interrelated and hold across our entire sample independent of whether or not the campaign met its funding target.

\subsection{Financial and campaign logistics}

The first emergent theme centers on the finances and logistics of a crowdfunding campaign. Interviewee responses can be disaggregated into three stages: preceding, during, and succeeding the actual campaign. Before deciding to use crowdfunding, many interviewees explained that general financial considerations must be made: it is important to consider whether or not the project is for-profit, 
the expected timeline of the project, and the amount of capital the project requires. Commercial and for-profit ventures often considered traditional sources like venture or debt-equity capital. Public science and not-for-profit projects often considered applying for university and government grants. Financing options depend upon project risk, and with space projects, interviewees explained that risk often decreases with time. With space projects in general, one interviewee explained that:

"Financing can come in different shapes and sizes... Quite often, the bigger the project, the wider the range of financing options... [It is important to] recognize that the project has different features, risks, amounts, and times, and therefore different types of funding from different types of sources."

Some explained that it is important to consider the practical financing strategy of a project in tandem with the research and development of the project itself and noted that a disconnect can exist between these two often siloed teams.

Some interviewees turned to crowdfunding only after unsuccessfully pursuing traditional financing options. For example, one interviewee explained:

"I tried crowdfunding because I had tried everything I knew, contacting venture capital firms... and going to banks... and hoped that maybe someone that has access to capital and is interested in space will see this and fund the project."

Others had previously secured funds and demonstrated the potential of their project, but utilized crowdfunding to finance an unforeseen shortage in capital near the final stages of project completion. Some used crowdfunding to help launch a project from scratch on a smaller scale in order to generate audience and financial support which could be leveraged to demonstrate the legitimacy of the project to venture capitalists and other potential investors. Interviewees' perceived that these decisions often depend on the level of capital necessary, the stage of the project, and the ultimate goals of the project team. It was stressed that crowdfunding is not a costless venture: marketing, time, and resources expended on a campaign should be weighed against the costs and benefits of alternative financing sources.

If crowdfunding is pursued, many respondents noted that the choice of platform can be important. Crowdfunding platforms have different fee structures, brand reputations, project location restrictions, and may or may not require that a campaign meet its funding goal in order to receive any of the donations. It is perceived that this decision is also a function of whether or not the project wishes to offer gifts in return for donations.

Finally, it was emphasized that the development of a public engagement strategy can help preemptively generate support before the campaign launches. For example, when asked about the perceived differences between projects which do or do not hit their funding target, one interviewee answered that:

"Success has to do with how they've sold it, the kind of awards they give back to people, the appeal to the general consumer, and the quality of the project and how well it's presented... The education and making people familiar with space and what's involved and just telling people what you're doing are [ways] we can help familiarize people with space...Saying to people, well, it's not rocket science, it's electronics and stuff people are doing in all these different industries around the world, but the only difference here is that it's in a satellite instead of in a box that's sitting in your lounge room."

Some felt that deciding which audiences to target (e.g. space enthusiasts, a given country's population, the global crowdfunding community) helps to guide a project marketing strategy, which might include 
contacting media outlets, promoting social media awareness, and translating a campaign's page into multiple languages. Here, internet and social media expertise were consistently described as useful.

The second stage is the actual launch of a campaign. Interviewees often felt that marketing continues to be crucial. The design of a campaign page which conveys the project team's passion, an easily digestible description of the project, and the potential and relatable impact of the project were all perceived to be important. Many felt that a short video detailing the project and campaign was useful. Interviewees often described the expected time commitment of this stage as akin to a full-time job in which responding to donor requests, questions, and comments, as well as posting updates about the project were all important in generating support. While a simple static campaign page with no video and limited media outreach could be sufficient to hit a relatively small funding target, it is perceived that this is insufficient to attract large levels of donations.

The third and final stage in a single campaign cycle is the post-campaign execution. If the campaign was successful, respondents explained that the fulfillment of promised gifts to donors is a time and resource consuming task which should not be underestimated, and some experienced delays in sending out promised gifts. Following up on technical expertise, hardware donations, and other promises made by donors is important for tapping the potential utility of a campaign. In addition to donor management, the actual execution of the project must also proceed and creators must continue to post updates about the progress of the project.

\subsection{Role of the crowd}

With financial and logistical considerations outlined, the second emergent theme centered on the role of the crowd. Personal networks, such as friends, family, and colleagues, were said to be helpful in diffusing the campaign's message and attracting donations. At the same time, it was perceived that the project must have wide appeal to attract larger audiences. Many respondents explained that the global space enthusiast community is relatively small but quite active and supportive of exploration projects. This space enthusiast community seems willing to donate across borders, and some respondents mentioned that global donors specifically requested that the project have an international identity. Most donations, however, seem to come from donors located within the same country of project origin.

The crowd attracted to a given project seems to be a function of the aforementioned marketing strategy. Some interviewees explained that a project can be impeded if the project is branded by, say, the media, as associated with a particular country when in actuality the project seeks a more international audience. This can be an impediment if the project seeks to build an audience and generate donations globally.

Many interviewees noted that the community building aspects of crowdfunding can rival its utility as a financing mechanism: some projects attracted donations of hardware and outside sponsorship, requests from donors to offer and contribute technical expertise, and developed an enthusiast following during and succeeding the campaign. One respondent explained that:

"[Crowdfunding] is a 24/7 job but also very fulfilling... When you reach out to people you also make a lot of connections... People hear about your project and you can meet a lot of experienced folks."

This led many creators to explain that potential donors may want to feel that they are somehow involved and "own" a piece of the project. This also hits on a general consensus among interviewees that online crowdfunding platforms allow for an ease of communication. Both positive and negative feedback could be readily communicated, leading many to describe crowdfunding as a learning process. Awareness and publicity were perceived to be an important benefit of crowdfunding relative to other 
financing mechanisms, and some explained that these dynamics helped to attract larger investors and institutional support.

When attempting to connect with a crowd in relation to a space exploration mission, a final consideration might be the selection of appropriate gifts. One interviewee explained:

"In a typical crowdfunding campaign you might say you're going to build a smart watch or make a movie and in return for sponsoring me you get the smart watch or the movie. In space, it's really tricky to get anything tangible back."

Whereas many crowdfunding projects in general might seek to create a consumer product, a challenge with space projects is the location of a suitable gift that is relevant to the project being executed. Many projects offered t-shirts and other small prizes, but some offered gifts unique to space, such as a microsatellite in the donor's name or an invitation to the mission control viewing gallery to watch a spacecraft launch or landing. Leveraging the unique aspects that space can offer donors is perceived to be important in drumming up support, but it can also be difficult to deliver a gift appropriate to the space science research being conducted.

\subsection{Unique aspects of space science research and exploration}

A third and final theme across our interviews related to the unique aspects of conducting space science research and exploration. Interviewees often discussed both the advantages and difficulties associated with conducting space science research which involved crowdfunding. It was perceived that the technical nature of the project required thoughtful and digestible explanations to lay audiences considering donating to the project. One respondent explained that "...you have to find the words to describe the project to non-specialists," and this was a common finding throughout the interviews.

Further, describing the potential applications of the research was felt to be important for helping audiences relate to the project. For example, one respondent described the difficulties in justifying the merits of the research and its seeming abstractness compared to researching other pressing perceived issues, like funding climate change research. Given the technical nature, some felt that institutional associations, such as with universities, research bodies, and non-governmental organizations, boosted audience trust in the legitimacy of the research.

Although justifying the project's merits and explaining the research in non-technical terms could be challenging, perception exists that space possesses qualities which are useful in inspiring audiences outside of the immediate space enthusiast community and across borders and nationalities in ways that say, a crowdfunded smart watch, might not. As one interviewee explained:

"It's easy...to communicate my passion about [space] and to say that this launch system is going to take humans to Mars one day... We're trying to get on the first mission... It's easy to say 'help me and my [project] get to the Moon;' that's a powerful phrase."

Many felt that space can excite potential donors about the prospects of the future of society, who might in turn be more likely to support the project.

In addition to the unique nature of space science research, projects involving the launch of a physical asset also presented possible advantages and disadvantages. Respondents explained that the prices of satellites, and particularly CubeSats, continue to decrease. Many felt that CubeSats increase access to space, because they require relatively moderate levels of capital and technical expertise. This was said to increase scope for enthusiasts, who might lack institutional affiliation and face difficulties in 
attracting government grants or private investment, to become involved in physical exploration. This finding, however, was not unique to enthusiasts. One interviewee explained that:

"What I would like is to have a sort of virtuous circle where you have a partnership between consumers who are doing something for fun or entertainment, and the scientists who have an opportunity to do research they couldn't otherwise do."

Crowdfunding's ability to support research that would otherwise go unfunded was a relatively consistent finding.

At the same time, many respondents described the expensive, risky, and time-consuming nature of conducting research and launching a physical object. The time scale of the execution of a space project can be much longer than the average crowdfunded product, and some mentioned cash shortages following the completion of the campaign. The public awareness and media attention often desired during a crowdfunding campaign also implies that both successes and failures are made particularly public.

Though few crowdfunding legal considerations emerged, potential concern surfaced surrounding import and export restrictions and domestic launch regulations dependent upon the project's location. Some felt that this exposes cleavages between the inherited structures, policies, and regulatory frameworks of Old Space and the changing nature of space exploration today.

In sum, most respondents felt that crowdfunding can indeed be a useful financing mechanism. Crowdfunding is likely to be insufficient to revolutionize the financing of large-scale, billion-dollar exploration projects, but it can possibly help to increase access to space in ways which historically were not possible.

\section{Discussion and conclusions}

This study departs from existing approaches found in the economics literature and focuses on the personal experiences of creators who have used crowdfunding. Further, we aim to add to present commentary on New Space by considering the social dimensions of the rise of nontraditional space actors. The above results offer the first primary account of creators' perceived experiences using crowdfunding for space projects. We now discuss these findings in light of the previously outlined theory to consider two implications of this phenomenon for today's space science research and exploration environment.

First, crowdfunding seems to both constrain and enable space science research and exploration. In line with the findings of Hui and Gerber [53], the job requirements of scientists expand to include social media and marketing expertise. Further, in line with Byrnes et al [54], our interviewees indicate that communicating and defending the merits of the research to a broader audience are important factors. Challenges with space, however, include the high risks, costs, and extended timelines often required. Increasing levels of public involvement in space exploration via crowdfunding results in a more democratic exploration environment, but it will be interesting to see whether projects with shorter timelines and lower capital requirements become disproportionately enabled.

Second, crowdfunding seems to both reproduce and challenge existing power structures of space. The public is not a static and isolated actor but is rather increasingly agential and embedded in the process of deciding which projects to fund. In so doing, the public helps to shape the nature of space exploration today. The actors identified by Kaminski [55], including politicians, scientists, and corporations, continue to be important, and the same networks and social capital historically valued in space 
exploration still matter. The lines of traditional roles, however, are increasingly blurred in cases where scientists, enthusiasts, and private ventures turn to crowdfunding while policymakers search for adapted regulatory mechanisms. The inherited structures of Old Space are being both navigated and pressed upon by New Space actors.

While these findings offer a preliminary assessment of the role of crowdfunding in financing space exploration, the study is limited by having only assessed this topic from the project creator side. Future research could add counterpoints and corroboration to these findings by assessing crowdfunded space projects from the perspective of donors. Furthermore, we set out to investigate the experiences of space project creators using a sociological approach. With little previous crowdfunded space exploration literature to draw upon, this exploratory study would be strengthened by future investigation using different methods and disciplinary approaches. For example, quantitative assessment could shed more light on the precise empirics of this trend. Finally, given that about two-thirds of our sample experienced successful campaigns, future research might uncover a broader range of experiences by locating more respondents with negative experiences. As more campaigns are launched over time, larger sample sizes will be possible which might remedy potential sample size limitations of this study.

Our results provide a preliminary basis to offer suggestions to individuals who may be considering utilizing crowdfunding for space science research and exploration. While much existing research focuses on the campaign itself, our interviews indicate that the pre-campaign and post-campaign stages require equally meticulous attention. When comparing to alternative financing sources, it is important to bear in mind that crowdfunding is not a costless venture. Time and resource costs, as well as the location of suitable gifts and the fulfillment of those gifts should be considered. Crowdfunding may not provide an adequate source of capital to bolster the multi-million-dollar scale which space often requires, but it does seem capable of funding projects in the $\$ 10,000$ to $\$ 100,000$ range and could be used to augment existing funds while increasing public awareness and involvement.

Finally, the important role of policymakers and regulators begs the consideration of policy implications and suggestions. The public may desire access to space in ways that differ from the projects of Old Space. Public appetites for risk, the debris emitted, and the ethics of space preservation versus exploitation will need to be managed by regulation which incentivizes responsible uses of space without stifling growth. To locate this balance, the proliferation of crowdfunded space projects offers a lens through which to view and appreciate the broader dynamics driving New Space activities. Animosity of previous political eras helped produce certain regulatory features governing space today, and these frameworks are being pressed upon by space actors who donate capital and hardware across borders. Enthusiasts who lack institutional affiliation but increasingly possess the crowdfunds and technical savvy necessary to participate in space should be given sensible and proportionate scope to enjoy access to exploration. More actors are entering space, but this only produces more questions: do barriers to entry exist dependent upon gender or socioeconomic status? How can policymakers ensure that individuals from less space-capable states are included? In essence, are we simply reproducing existing issues and societal inequalities into space?

In his 2013 Nobel Prize lecture, Robert Shiller describes economists' growing acceptance of sociological factors in the post-2007 financial crisis era [56]. He points out that crowdfunding might enable social and aspirational projects previously not possible, but that crowdfunding might also lead to runaway bubbles and investor abuse, thus requiring careful regulation [57]. This article ends on a similar cautiously optimistic note. The democratizing effects of crowdfunding catalyze space exploration in new ways but can also lend support to projects which never leave the launch pad. Perhaps considering the experiences of individuals who have previously used this mechanism can help to avoid the latter. 


\section{Acknowledgements}

The authors extend especial thanks to the individuals who agreed to be interviewed for this study. We also thank Jonathan Kennedy and Christoph Beischl for providing invaluable comments on earlier versions of the paper, as well as two anonymous reviewers for their feedback and suggestions for improvement. Any remaining errors are the authors' alone.

\section{Funding}

This research did not receive any specific grant from funding agencies in the public, commercial, or not-for-profit sectors.

\section{Appendix: Interviewees and project affiliations}

Nick Orenstein, Veggies on Mars, Mars Desert Research Station

Suzanne Flinkenflögel, Mars One

Alex McFarlane, Mission Space

Alexander Shaenko, Mayak

Zac Manchester, KickSat

Craig Russell, ECLIPSE, Space Operations Inc.

Tim DeBenedictis, SkyCube, Southern Stars

Mads Wilson, Copenhagen Suborbitals

David Iron, Lunar Mission One

Rachel Weinberg, MIT KitCube Lunar Orbiter

Michael Johnson, KickSat and PocketSpacecraft.com

Mehdi Sabzalian, Space Concordia

Christopher Robson, AlbertaSat

And one individual who wishes to remain anonymous

\section{References}

[1] Crawford, IA (2004) “The scientific case for renewed human activities on the Moon," Space Policy, 20(2): 91-97.

[2] Burns, JA (2007) “Sputnik, space, and me,” Nat. Phys., 3: 664-668.

[3] Logsdon, JM (2015) "Why did the United States retreat from the Moon?," Space Policy, 32: 2.

[4] Chang, K (Sept 2014) "2 Companies Will Take Americans to Space Station," New York Times, Accessed from: http://www.nytimes.com/2014/09/17/science/space/boeing-and-spacex-win-contractsto-carry-americans-to-space-station.html 
[5] Verhovek, SH (Nov 2014) "Not a Flight of Fancy," New York Times, Accessed from: http://www.nytimes.com/2014/11/04/opinion/space-tourism-isnt-frivolous-or-impossible.html

[6] Boroujerdi, RD \& C Wolf (Dec 2015) "What if I Told You...: Themes, Dreams and Flying Machines," Emerging Theme Radar, Goldman Sachs Equity Research, p. 6, Accessed from: http://www .goldmansachs.com/our-thinking/pages/macroeconomic-insights-folder/what-if-i-toldyou/report.pdf

[7] Agrawal, AK, C Catalini \& A Goldfarb (2014) "Some simple economics of crowdfunding," Innov. Policy and the Econ., 14(1): 65.

[8] Zheng, H, D Li, J Wu \& Y Xu (2014) "The role of multidimensional social capital in crowdfunding: A comparative study in China and US," Inf. \& Manag., 51(4): 488-496.

[9] Agrawal, AK, C Catalini \& A Goldfarb (2015) "Crowdfunding: Geography, Social Networks, and the Timing of Investment Decisions," J. of Econ. \& Manag. Strat., 24(2): 253-274.

[10] Kay, WD (1995) Can Democracies Fly in Space? The Challenge of Revitalizing the US Space Program, Westport, CT: Greenwood Publishing Group.

[11] Peter, N (2006) “The changing geopolitics of space activities," Space Policy, 22(2): 100-109.

[12] Burns, JA (2007), above ref. [2]

[13] Jarritt, I, W Peeters \& M Simpson (2010) "Space financing in the aftermath of the financial crisis," Space Policy, 26(2): 119-120.

[14] Kessler, H \& W Peeters (2011) "Man and space - The Isle of Man, the IISC and the new space economy," Space Policy, 27(4): 222.

[15] SPACE Act: US Commercial Space Launch Competitiveness Act - Section 402: HR 2262, available at: https://www.congress.gov/bill/114th-congress/house- bill/2262/text (last accessed: 05 July 2016).

[16] Kessler, H \& W Peeters (2011), above ref. [14]

[17] Kessler, H \& W Peeters (2011), above ref. [14]

[18] Tronchetti, F (2015) "The Space Resource Exploration and Utilization Act: A move forward or a step back?" Space Policy, 34: 6.

[19] Siddique, H (May 2016) "Driverless cars, drones and spaceport to feature in Queen's speech," The Guardian, Accessed from: http://www.theguardian.com/politics/2016/may/15/queens-speechdriverless-cars-drones-uk-spaceport

[20] Buck, J (Nov 2013) "NASA Helps Launch Student-Built Satellites as Part of CubeSat Launch Initiative," NASA Press Release, Accessed from: http://www.nasa.gov/content/nasa-helps-launchstudent-built-satellites-as-part-of-cubesat-launch-initiative

[21] Platzer, P \& K Klausner (2016) "Crowdfunding for Small Satellites," in I Marboe (ed) Small Satellites: Regualtory Challenges and Chances, Leiden: Brill Nijhoff. 
[22] Belleflamme, P, T Lambert \& A Schwienbacher (2014) "Crowdfunding: Tapping the Right Crowd," J. of Bus. Ventur., 29(5): 586.

[23] Agrawal, AK, C Catalini \& A Goldfarb (2014), above ref. [7] p. 67.

[24] Agrawal, AK, C Catalini \& A Goldfarb (2015), above ref. [9] p. 254.

[25] Agrawal, AK, C Catalini \& A Goldfarb (2014), above ref. [7] p. 65-67.

[26] Kuppuswamy, V \& BL Bayus (2015) "Crowdfunding Creative Ideas: The Dynamics of Project Backers on Kickstarter," UNC Kenan-Flagler Research Paper No. 2013-15, Available at SSRN: http://papers.ssrn.com/sol3/papers.cfm?abstract_id=2234765

[27] Mollick, E (2014) "The dynamics of crowdfunding: An exploratory study," J. of Bus. Ventur., 29(1): 1-16.

[28] Zheng, H, D Li, J Wu \& Y Xu (2014), above ref. [8]

[29] Agrawal, AK, C Catalini \& A Goldfarb (2014), above ref. [7]

[30] Meer, J (2014) "Effects of the price of charitable giving: Evidence from an online crowdfunding platform," J. of Econ. Behav. \& Organ., 103: 113-124.

[31] Platzer, P \& K Klausner (2016), above ref. [21] p. 361.

[32] Rosenberg, Z (Sept 2014) “Space Crowdfunding: What's the Secret?" Air \& Space Magazine (Smithsonian), Accessed from: http://www airspacemag.com/daily-planet/space-crowdfunding-whatssecret-180952649/?no-ist

[33] McKee, M (July 2013) "Kickstarter Campaign Wants to Send Tiny Satellites out of Earth Orbit," MIT Technology Review, Accessed from: https://www.technologyreview.com/s/517186/kickstartercampaign-wants-to-send-tiny-satellites-out-of-earth-orbit/

[34] Wall, M (2015) "Cosmic Kickstarter: How Crowdfunding Helps New Space Projects Launch," Space.com. Accessed from: http://www.space.com/29587-crowdfunding-space-projectskickstarter.html

[35] Harris, HE \& P Russo (2015) "The Influence of Social Movements on Space Astronomy Policy: The Cases of 'Hubble Huggers,' JWST's 'Science Warriors,' and the ISEE-3 'Reboot Team,'” Space Policy, 31: 3 .

[36] Sclove, R (1995) Democracy and Technology, New York: Guilford Press.

[37] de Jong, M \& M Mentzel (2001) "Policy and science: options for democratization in European countries," Sci. \& Public Policy, 28(6): 403-412.

[38] Irwin, A and M Michael (2003) Science, Social Theory \& Public Knowledge, McGraw-Hill Education (UK).

[39] Schmandt, J \& JE Katz (1986) “The Scientific State: A Theory with Hypotheses," Sci., Tech., \& Human Values, 11(1): 40-52. 
[40] Hagendijk, R and A Irwin (2006) "Public deliberation and governance: Engaging with science and technology in contemporary Europe," Minerva, 44(2): 167-184.

[41] Turnhout, E, M Stuiver, J Klostermann, B Harms \& C Leeuwis (2013) "New roles of science in society: Different repertoires of knowledge brokering," Sci. \& Public Policy, 40(3): 354.

[42] Laird, FN (1993) "Participatory Analysis, Democracy, and Technological Decision Making," Sci., Tech., \& Human Values, 18(3): 356.

[43] Biegelbauer, P \& J Hansen (2011) "Democratic theory and citizen participation: democracy models in the evaluation of public participation in science and technology," Sci.\& Public Policy, 38(8): 591.

[44] Derrick, GE \& V Pavone (2013) "Democratising research evaluation: Achieving greater public engagement with bibliometrics-informed peer review," Sci. \& Public Policy, 40(5): 563-575.

[45] Turnhout, E, M Stuiver, J Klostermann, B Harms \& C Leeuwis (2013), above ref. [41]

[46] Fochler, M (2016) "Beyond and between academia and business: How Austrian biotechnology researchers describe high-tech startup companies as spaces of knowledge production," Soc.Stud. of Sci., 46(2): 276.

[47] Fochler, M (2016), above ref. [46]

[48] Lehoux, P, FA Miller, G Daudelin \& DR Urbach (2016) "How venture capitalists decide which new medical technologies come to exist," Sci.\& Public Policy, 43(3): 375-385.

[49] Byrnes, JE, J Ranganathan, BL Walker \& Z Faulkes (2014) "To crowdfund research, scientists must build an audience for their work," PLoS One, 9(12): 1-29.

[50] Hui, JS \& EM Gerber (2015) "Crowdfunding Science: Sharing Research with an Extended Audience," Proceedings of the 18 ACM Conference on Computer Supported Cooperative Work \& Social Computing, 31-43, ACM. DOI: 10.1145/2675133.2675188

[51] Kaminski, AP (2012) "Can the demos make a difference? Prospects for participatory democracy in shaping the future course of US space exploration," Space Policy, 28(4): 225-233.

[52] JOBS Act: The Jumpstart Our Business Startups Act - HR 3606, available at: https://www.congress.gov/bill/112th-congress/house- bill/3606 (last accessed: 05 July 2016).

[53] Hui, JS \& EM Gerber (2015), above ref. [50]

[54] Byrnes, JE, J Ranganathan, BL Walker \& Z Faulkes (2014), above ref. [49]

[55] Kaminski, AP (2012), above ref. [51]

[56] Shiller, RJ (2013) “Speculative Asset Prices,” Am. Econ. Rev., 104(6): 1486.

[57] Shiller, RJ (2013), above ref. [56] p. 1510. 